\title{
As propostas culturais, econômicas e políticas apresentadas nas primeiras Conferências Pan- Americanas
}

\author{
The cultural, economic and political proposals presented in the first \\ Pan-American Conferences
}

DULCI, Tereza Maria Spyer. As Conferências Pan-Americanas (1889 a 1928): Identidades, União Aduaneira e Arbitragem. São Paulo: Alameda, 2013. 238p.

\section{Paulo Alves Pereira Júnior}

paulopereira_pf@hotmail.com

Mestrando em História - Bolsista FAPESP

Universidade Estadual Paulista (UNESP - Assis)

Rua João M. Salgueiro, 63 , Ed. Antônio Gallo, ap. 03

13660-000 - Porto Ferreira - São Paulo

Brasil

Palavras-chave

História da América; Historiografia latino-americana; Historiografia norte-americana.

Keywords

American historiography; Latin American historiography; American historiography. 
A criação do Mercado Comum do Sul e da União das Nações Sul-Americanas estimulou o debate acerca das relações de aproximações e distanciamentos entre o Brasil e os outros países americanos e, também, das probabilidades de integração econômica, política e cultural no continente. Para compreender tal movimento, Tereza Maria Spyer Dulci elaborou uma dissertação, apresentada à Universidade de São Paulo (USP) em 2008, que analisou a participação brasileira nas seis primeiras Conferências Pan-Americanas. Utilizando-se de uma sólida documentação, a autora externou dois temas amplamente discutidos nesses congressos: a União Aduaneira e a arbitragem. Ademais, destacou as propostas identitárias elucidadas pelos Estados Unidos da América (EUA) e pela Argentina. Buscando alcançar um público-leitor além do círculo acadêmico, esse trabalho foi transformado em livro no ano de 2013. As Conferências Pan-Americanas (1889 a 1928): identidades, união aduaneira e arbitragem foi publicada pela editora Alameda e pertence à coleção Teses do Programa de Pós-Graduação em História Social da USP.

Fracionado em quatro capítulos, a obra inicia-se com um texto introdutório, o qual destaca o escopo do estudo, realiza um balanço bibliográfico a respeito das Conferências Pan-Americanas e apresenta a abordagem teórica utilizada, pautada no campo da História Política e nas perspectivas enunciadas pela crítica pós-colonial. No primeiro capítulo, a autora explana a trajetória dos seis primeiros conclaves, evidenciando seus principais objetivos e resultados. Já no segundo, analisa os projetos identitários constituídos durante as conferências estudadas e o posicionamento da diplomacia brasileira a respeito de tais discursos. As discussões referentes à união aduaneira e às propostas integracionistas apresentadas nessas assembleias são abordadas no terceiro capítulo. Os debates sobre a utilização do arbitramento como uma forma de solucionar os conflitos internacionais foram elucidados no último capítulo.

As Conferências Pan-Americanas ocorreram entre 1889 e 1948 e tiveram como sede, respectivamente, as cidades de Washington, Cidade do México, Rio de Janeiro, Buenos Aires, Santiago, Havana, Montevidéu, Lima e Bogotá. O objetivo dessas assembleias era unir os países americanos através do fortalecimento político-econômico no continente. Após o fim da Guerra de Secessão (18611865) e da Guerra Hispano-Americana de 1898, o eixo da política externa estadunidense moveu-se para a América Central e o Caribe. Ademais, esse movimento pretendeu transformar o país no líder continental. Para lograr com tal proposta, ao final do século XIX os EUA convidaram as outras nações americanas para um evento que tratasse de questões relacionadas ao comércio internacional e à arbitragem nas disputas regionais. Dessa forma, realizou-se entre 02 de outubro de 1889 e 19 de abril de 1890 a Primeira Conferência Pan-Americana. Contando com a participação de dezoito delegações, o evento discutiu a adoção da arbitragem, o desenvolvimento comercial entre os países e a elaboração da união aduaneira. Por conta da postura opositora da delegação argentina, grande parte dessas propostas foi derrotada.

Sucedeu-se na Cidade do México, de 22 de outubro de 1901 a 22 de janeiro de 1902, a Segunda Conferência, formada por dezenove delegações. 
Debateu-se alguns pontos da assembleia passada e assuntos relacionados aos meios de proteção industrial e comercial, além de outros temas. Ao final, aprovou-se resoluções associadas ao arbitramento e ao direito internacional. 0 conclave posterior ocorreu no Rio de Janeiro entre 23 e 27 de agosto de 1906 e foi composto por dezenove delegações. Esgrimiu-se a questão do arbitramento, das dívidas públicas, da codificação do Direito Internacional Público e Privado, das leis aduaneiras e consulares, da polícia sanitária, da estrada de ferro panamericana e da propriedade literária. A assembleia findou-se com a aprovação de tratados de reciprocidade comercial entre os países americanos e resoluções acerca dos direitos autorais.

De 12 de julho a 27 de agosto de 1910, vinte delegações reuniram-se Buenos Aires para a quarta edição do evento. Discutiu-se o intercâmbio de professores e de estudantes e a comemoração do centenário de independência dos países hispano-americanos, dentre outros temas. O principal logro desse encontro foi a ratificação dos assuntos debatidos no conclave anterior e a aprovação das resoluções sobre os direitos autorais, as patentes, a saúde pública e o direito internacional. Em função da Primeira Guerra Mundial, a Quinta Conferência foi realizada após um intervalo de treze anos. Dezoito delegações fizeram parte dessa convenção, ocorrida entre 25 de março e 03 de maio de 1923 em Santiago. Abordou-se as medidas preventivas de enfermidades infecciosas, a promoção de arbitragem comercial entre cidadãos de diferentes países e o acordo sobre leis e regulamentação da comunicação marítima, terrestre e aérea.

A assembleia seguinte ocorreu em Havana de 16 de janeiro a 20 de fevereiro de 1928 e contou com a participação de vinte e uma delegações. Os principais assuntos abordados foram a União Pan-Americana, os problemas comunicacionais e socioeconômicos e a ordem jurídica interamericana. O resultado fundamental desse encontro foi a aprovação do Código de Direito Internacional Privado Americano que estabeleceu uma normativa geral para evitar conflitos entre as leis nacionais e internacionais.

As seis assembleias proporcionaram uma rede de solidariedade regional e desenvolveram um espaço de disputa entre as nações americanas. Em tais conclaves, apesar de ter existido um protagonismo estadunidense que privilegiou pautas de seus interesses e manteve uma política de troca de votos - nos bastidores - por acordos comerciais e de intervenção e anexação de territórios na América Latina e no Caribe, muitos países latino-americanos rechaçaram as propostas que poderiam prejudicá-los.

Nas Conferências Pan-Americanas configurou-se duas construções identitárias: o pan-americanismo e o latino-americanismo. O primeiro era o oficial das assembleias, constituído pelos delegados estadunidenses. Para construir uma identidade continental, os Estados Unidos apresentaram projetos de financiamento e intercambio entre as universidades da região com o objetivo de aprofundar as investigações sobre os elementos histórico-culturais da América e legitimar um passado comum. Por sua vez, o segundo discurso foi propagado pelos representantes argentinos nas reuniões com a intenção de impedir as intervenções dos EUA e de direcionar a Argentina à liderança 
da América Latina. Essa proposta abrangeu as nações latino-americanas que atuaram nas assembleias e excluiu os países não hispânicos.

Sobre as disputas de identidades, a diplomacia brasileira adotou uma postura neutra, aproximando-se do discurso pan-americano ou latino-americano quando Ihe convinha. Para aumentar sua influência nas conferências, o Brasil acercou-se dos Estados Unidos, como ocorreu no caso do arbitramento. Em outras ocasiões, avizinhou-se dos outros países da América Latina, principalmente quando envolvia interesses econômicos, como a proposta de união aduaneira. Esse movimento ficou conspícuo nos conflitos travados entre Joaquim Nabuco, que defendeu veementemente o pan-americanismo e a liderança estadunidense no continente, e Manoel de Oliveira Lima, que criticou o projeto identitário fomentado pelos Estados Unidos e afirmou que o Brasil deveria relacionar-se mais com os Estados ibero-americanos para conter a política intervencionista dos EUA.

A temática sobre a união aduaneira surgiu antes das Conferências PanAmericanas, uma vez que existiram projetos de pacto regional desde o início do século XIX. Nesse período, diversos tratados de navegação, de comércio e de alianças foram assinados pelas nações americanas. Por conta dos conflitos internos, os Estados Unidos não participaram desses acordos. Após a Guerra da Secessão, a diplomacia estadunidense desenvolveu uma política econômica que pretendeu escoar seus produtos nos mercados americanos. Na assembleia de Washington, os EUA incluíram uma pauta no programa que discutiu a elaboração de uma união aduaneira que englobasse todo o continente sem barreiras físicas ou materiais entre os territórios nacionais para que bens, capitais e serviços circulassem.

O governo estadunidense esperava que sua proposta fosse bem recebida pelas delegações dos outros países, o que não ocorreu, já que foi duramente criticada pelos representantes chilenos e argentinos e observada com desconfiança pelos outros delegados que acreditavam que tal medida poderia prejudicar os acordos bilaterais na região. Apesar de a questão não ter logrado em tais congressos, o tema relacionado à união aduaneira fez parte de muitos debates diplomáticos do final do século XIX e das primeiras décadas da centúria passada.

Nas conferências posteriores, os Estados Unidos centralizaram suas discussões em torno dos tratados comerciais bilaterais que auxiliassem no escoamento de suas mercadorias para os países latino-americanos e debateram as propostas de união aduaneira nas entrelinhas dos programas, com o intuito de diminuir o impacto da derrota na primeira assembleia. Dessa forma, incentivaram a elaboração de alianças de reciprocidade e projetos integracionistas, objetivando facilitar a constituição de uma união aduaneira.

Pretendendo fomentar o desenvolvimento das relações econômicas entre as nações americanas, discutiu-se nos conclaves os seguintes projetos: Câmaras de Comércio e Propaganda; Sociedades Anônimas; Banco Pan-Americano; União Monetária; Regulamentos Aduaneiros; Codificação do Direito Internacional Público e Privado; Código Sanitário; Regulamentação da Propriedade Literária e Artística, Patentes e Marcas de Fábrica e Comércio; e Estrada de Ferro PanAmericana. Tais propostas não foram consideradas praticáveis por todos os 
delegados presentes nos eventos, apesar de elas levarem em consideração os interesses particulares de cada nação.

O tema do arbitramento tornou-se uma questão central nas conferências. Ao final do século XIX, havia um conflito de influências entre os países que não aceitavam ter o seu poder inferiorizado no continente americano, como a Inglaterra - representada pelos delegados argentinos - e a ambição estadunidense de intervir nos países latino-americanos e caribenhos. Além disso, os EUA pretendiam se tornar os árbitros nas disputas entre as nações da América Latina, substituindo a Europa e assegurando sua influência política. Desde o conclave da Cidade do México, debateu-se sobre a adoção da arbitragem obrigatória ou voluntária, tendo a Argentina defendida a primeira ramificação e os Estados Unidos endossado a segunda. Dessa forma, os Estados americanos possuíam distintas posições, uns aceitando e outros rechaçando o arbitramento. Tais posturas foram determinadas pelos interesses particulares de cada país.

Os Estados Unidos apresentaram uma posição dúbia em relação ao tema, uma vez que defendiam a paz na região desde que os conflitos fossem gerenciados por eles e, caso houvesse a necessidade de garantir a paz em alguma nação, valer-se-iam do "direito de conquista". Já o Brasil utilizou esse recurso para resolver os litígios pendentes acerca da delimitação fronteiriça. Por sua vez, a Argentina envolveu-se nessas discussões para diminuir o avanço da influência político-econômica dos EUA na América Latina. Na Conferência de Washington foi assinado um tratado estabelecendo a arbitragem como um princípio do Direito Internacional Americano para as divergências entre as nações americanas. Além disso, elucidava a questão do arbitramento envolvendo os países americanos e os Estados europeus.

Entretanto, tal documento não foi ratificado pelos membros do conclave e discutiu-se a elaboração de um tratado que garantisse às partes em litígio o direito de submeterem reclamações por danos pecuniários não solucionados por meios diplomáticos. Amplamente debatido nos eventos, o assunto relacionado à arbitragem malogrou com a eclosão da Primeira Guerra Mundial. O projeto conciliador do arbitramento elucidado nas Conferências Pan-Americanas era tênue e, por essa razão, não obteve consenso entre os participantes.

Tereza Maria Spyer Dulci destaca que, ao contrário do que a bibliografia sobre o assunto elucida, os Estados Unidos não tiveram suas propostas totalmente aceitas nas assembleias, já que os debates sobre a união aduaneira e a arbitragem não surtiram os efeitos esperados. Dessa forma, compreende as Conferências Pan-Americanas como locais que acolheram conflitos entre o "centro" de poder estadunidense e a oposição das "periferias" latino-americanas e caribenhas.

A autora apresenta ao público-leitor uma pesquisa original que contou com diversas fontes e com uma vasta bibliografia em língua espanhola, inglesa e portuguesa. A maioria dessas fontes é composta por documentos elaborados pelo Ministério das Relações Exteriores do Brasil, como ofícios, dossiês, telegramas, recibos, recortes de reportagens jornalísticas, protocolos, dentre outros. Tais materiais foram encontrados no Arquivo Histórico do 
Itamaraty, na cidade do Rio de Janeiro, no Centro de Documentação e Divisão de Comunicações e Arquivo do Ministério das Relações Exteriores do Brasil, em Brasília, e na Biblioteca Embaixador Antonio Francisco Azeredo da Silveira, também localizada na capital brasileira.

Apesar dos méritos, o trabalho necessita de uma discussão mais aprofundada acerca das propostas de identidade, da elaboração de união aduaneira e dos projetos de arbitragem nas Conferências Pan-Americanas. Ademais, seria necessário levar em consideração a perspectiva de outros países americanos que participaram dessas assembleias, a fim de constatar o impacto desses eventos em suas políticas diplomáticas, econômicas e culturais. A eclosão da Guerra do Chaco (1932-1935), conflito bélico entre Bolívia e Paraguai, fomentou a polêmica em torno do arbitramento? Qual a importância da Confederación Universitaria Centroamericana, fundada em 1948, para os projetos integracionistas do continente? A criação da Associação Latino-Americana de Livre Comércio, na década de 1960, foi influenciada pelas discussões apresentadas nas conferências? Tais questões podem ser esclarecidas em investigações futuras sobre o tema em questão. 